\title{
The illness of women and men with sickle cell disease: a Grounded Theory study ${ }^{1}$
}

\author{
Rosa Cândida Cordeiro \\ Silvia Lúcia Ferreira ${ }^{3}$ \\ Ane Caroline da Cruz Santos ${ }^{4}$
}

\begin{abstract}
Objective: to understand the meanings given by women and men with sickle cell disease on the illness experience. Method: analytical study with a qualitative approach, conducted with 17 adults with sickle cell disease using the Theory Based on Data, or Grounded Theory, as theoretical-methodological referential. Data were collected between the years of 2012 and 2013, in an individual in-depth interview. All the interviews were recorded and analyzed according to the Grounded Theory comparative analysis technique. Results: data show four categories which group the experience of illness, the feelings experienced and the path to living with sickle cell disease. Conclusions: it was possible to understand that the experience was built by a process in which these people redefined the meaning of their lives, applying new directions to life and to care regarding the experience of the illness. In the context of chronic disease, the nurse's care is also seen in this study as a foundation, providing attention, directions, and guidance through the required confrontations. Understanding the experience lived by these people, it is possible to enlarge the dimensions and the essence of nursing care required throughout life.
\end{abstract}

Descriptors: Chronic Disease; Anemia, Sickle Cell; Nursing.

\footnotetext{
${ }^{1}$ Paper extracted from doctoral dissertation "Experience of illness in women and men with sickle cell disease", presented to Escola de Enfermagem, Universidade Federal da Bahia, Salvador, BA, Brazil. Supported by Fundação de Amparo à Pesquisa do Estado da Bahia (FAPESB), Brazil, process \# PET 0009/2010.

2 PhD, Adjunct Professor, Escola de Enfermagem, Universidade Federal do Recôncavo da Bahia, Santo Antônio de Jesus, BA, Brazil. Scholarship holder from Coordenação de Aperfeiçoamento de Pessoal de Nível Superior (CAPES), Brazil.

3 PhD, Adjunct Professor, Escola de Enfermagem, Universidade Federal da Bahia, Salvador, BA, Brazil.

${ }^{4}$ Master's student, Escola de Enfermagem, Universidade Federal da Bahia, Salvador, BA, Brazil. Scholarship holder from Coordenação de Aperfeiçoamento de Pessoal de Nível Superior (CAPES), Brazil.
}

Corresponding Author:

Ane Caroline da Cruz Santos

Universidade Federal da Bahia. Escola de Enfermagem

Av. Dr. Augusto Viana, S/N

Bairro: Canela

CEP: 40110-060, Salvador, BA, Brasil

E-mail: anecaroline_ef@hotmail.com
Copyright @ 2015 Revista Latino-Americana de Enfermagem This is an Open Access article distributed under the terms of the Creative Commons Attribution Non-Commercial License (CC BY-NC).

This license lets others distribute, remix, tweak, and build upon your work non-commercially, and although their new works must also acknowledge you and be non-commercial, they don't have to license their derivative works on the same terms. 


\section{Introduction}

The personal and social experience of illness is built through social and cultural processes experienced every day by facing each phase that sickle cell disease is intensified. The experience is singular and integrates multiple meanings, based on the experience of each person in their social-cultural contexts ${ }^{(1)}$.

In this sense, the experience lists the shared meanings between people with their groups, the complaints, the suffering, the symptoms, the manifestations, the practices of the health services and their relationships with people in social groups and institutions.

The World Health Organization (WHO) recognizes sickle cell disease as a priority for public health, since there are inequities in access to health services for those people in different parts of the world. In Brazil, this disease is prevalent among Afro-descendants in

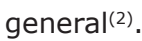

In Brazil, about 3,500 children/year or one child every 1,000 children are born with sickle cell disease. The state of Bahia, in the Northeastern region of the country, has the highest incidence of the disease, with a case for each 650 live births and a person with sickle cell trait for each 17 births $^{(2)}$.

Data from the Pan American Health Organization refer to increasing the life expectancy of people with sickle cell disease (from 10 to 50 years), possible in recent decades after important preventive and therapeutic interventions, which transformed it in a chronic disease ${ }^{(3)}$

The process of illness by a genetic, degenerative and chronic disease implies changes in the way of living and everyday life, especially due to requiring continuous and prolonged care, focused on the different complications that appear throughout life, such as joint pain and musculoskeletal injuries with progressive loss of functional capacity.

The impact of sickle cell disease in adult life indicates that women and men who have it need health services often, rely on an aid of specialized services, have restricted labor activity with reduced participation in the household budget, and early retirement(3).

We considered that understanding the illness experience of people with sickle cell disease is fundamental to health professionals, and in particular to nurses, in order to organize the nursing care to expand access of this population group for assistance. In this sense, it is possible to wonder what are the meanings assigned by women and men about the experience of living with sickle cell disease. The objective established was to understand the meanings assigned by women and men with sickle cell disease on the illness experience.

\section{Methods}

This is an analytical study with a qualitative approach that uses Theory Based on Data as methodological referential(4).

Adults diagnosed with sickle cell disease aged between 18 and 49 years participated in this study. The selection of the participants was both intentional and theoretical, and the first people were invited after a survey with the community health agents, and then they indicated other people.

Data collection was developed in three municipalities in the state of Bahia, Northeast region of Brazil, between the years of 2012 and 2013. The research team was composed of researcher nurses with doctorate and master's degrees, who had extensive experience in this area of knowledge.

Data were collected through personal in depth interviews ${ }^{(5)}$, carried out in the respondents households. The interviews were initiated with nine people with sickle cell disease, in which participants were requested to report their experience of living with the disease in their daily lives.

The researchers forwarded the remaining issues according to the responses of the people interviewed. The second group consisted of eight people, considering the suggestions, ideas and questions that emerged from the data that were coded and analyzed from the first group.

The sample size was based on the saturation of the statements contained in the interviews. All seventeen interviews were recorded, transcribed and analyzed, according to the comparative analysis technique based on the Theory Based on Data by following these steps: collection of empirical data, formation of concepts, development of concepts, modified and integrated concepts, and research report.

The data were analyzed based on the Grounded Theory analysis systematic, which relied on constant comparison of the responses from the various participants. The Grounded Theory (or Theory Based on Data) was created by the sociologists Glaser and Strauss, being a qualitative technique that organizes systematically the data collected and analyzed in the course of the research, performing the open encoding and subsequent categorization(6). 
During the open encoding, data were analyzed line by line, examined, and then compared for similarities and differences. Through this process, the object was questioned and explored, enabling new discoveries and the emergence of analysis categories.

Coded data were grouped by similarity. Each category was considered saturated when it was not possible to add new data. Such procedure then gave rise to the categories relating to the illness experience for women and men with sickle cell disease.

In order to maintain the accuracy of the study, the following strategies were used: make the interviews available after transcription for all participants, to ascertain whether they were represented in the way the data was being analyzed, and consolidated criteria were used for the Qualitative Research Reporting (COREQ) as a support tool. This consists of a list of 32 verification items concerning the research team, the research project, and the analysis of the data in relation to qualitative research methods ${ }^{(7)}$.

National and international standards of ethics in research involving humans were met at all stages of the research. The respondents had the option of conducting the interview either in the presence of family or separately to avoid constraints and allow more privacy and secrecy of information, preserving the integrity and welfare of the individuals.

All people interviewed had the right to listen to their testimonies shortly after the recording, and they could add or render void any information. The research was funded by FAPESB (Research Support Foundation for the State of Bahia) and counted with a fellowship from CNPq (National Council of Scientific and Technological Development). It was approved by the Research Ethics Committee of the Nursing School of the Federal University of Bahia, through Ordinance n०124,288/2012.

All participants signed a Free and Informed Consent Form. The statements were identified by the letter I, related to the interview, followed by the corresponding numbers.

\section{Results}

According to the considered referential, the resources created by these people to live with the process of illness were represented by four categories, namely: realizing the sickness - the experience of the first moment; getting to know sickle cell disease better and seeking for care; revealing feelings that influence the course of the illness experience; and living between limits and overruns - redefining life from care.

The category "realizing the illness: the experience of the first moment" presents itself from the perception of the first signs and symptoms, in which people realize that something is wrong, and try to control the anguish through various care actions that they perform at home. The bones begin to tingle, then begins to irradiate, a pain like that seems to be breaking the bones, this is how it starts, and I realize that I'm not well (I01).

In that category, different perceptions between women and men are revealed. Thus, women are on alert when they notice their image in the mirror has changed. They describe a set of symptoms that are more related to physical appearance (change in self-image), and men are worried about loss of muscle strength, such as weakness.

That does not mean that there are different symptoms between women and men, but the perception of the presence of the symptom and its description was different. My eyes and my skin get yellow, it is really weird (I01). I looked in the mirror and saw the eye get yellow and yellower, like egg yolk (I02). I felt a lot of weakness, I could not keep myself strong, and had body aches all over, in the arm and legs. Too much pain (I03).

The category "getting to know sickle cell disease better and seeking for care" reveals that after the onset of signs and symptoms and the attempts to restore their health through care within the family scope, they acknowledge that it is not possible to deal with the various situations that are showing without using the services of health institutions. They understand that they need to act in the sense of taking care of their health so life can get back to normal. I had a cup of tea, massaged myself and lay waiting for the body to react, when I saw the pain getting worse and that there was nothing else $I$ could do, I had to find a doctor (I05).

In that context, nurses are acknowledged as the team that is on the front line of care, because when they arrive at emergency services they are always accompanied by someone from the nursing staff, and therefore, the nurse occupies a position of recognition, of importance, of the one who gets there first. Nursing is on the front line in an emergency service. The technician and the nurse that are there with the patient constantly, that provide the saline solution, which check the patient out, which are closest to him. The nurse admits me and treats me very well, that made a difference (I06). The nurse talks to you, watches, examines you, and when the doctor arrives he already knows everything about you and just prescribes the medication (I07). 
Thus, nursing care is not lived without conflict in emergency services, for when multiple venous punctures are needed, the patients are charged and found guilty. For us who have sickle cell disease, the veins disappear, we do not have enough to put the saline solution, the venous access; so in the process of finding a vein, it generates a stress on the nurses, they think that we are changing position. Sometimes the simple fact that you have anemia causes the vein to disappear (I08).

The category "revealing feelings that influence the course of the illness experience" demonstrates that the meaning of the illness can be changed several times in the light of the events that occur during the experience and the events related to the therapy.

In this context, it is identified that it is hard to live with a disease that leads to discrimination in various sectors of society, within the family, at work, and in health services. Besides, often moving them away from the access to certain public goods, hindering a better quality of life. We are discriminated by the color of our skin. It is hard to deal with a disease that leads to this (I08). I have a friend who did not date due to the problem she had, many people did not approach people who have sickle cell disease, they do not accept us (109). The last thing you want is to be discriminated, you feel diminished (I11). If people would invest as they should regarless of being black, I think it would be much better for us, access would be good, treatment, care and quality of life were going to change (I07).

Finally, the category "living between limits and overruns - redefining life from the care" emerged, revealing that regardless of what is the prospect considered and the limitations experienced, experience counts victories that were conquests beyond the illness and are events that drives them to continue. A person with chronic disease will always have limitations with the body, but it is not that she cannot do anything (I06). I used to like going to the beach and lay around in the sun, today I do not do that, I go to the beach but I know that if I keep taking all that sun exposure and then go into the water, I am going to have pain crisis and I know my limitations (I07). The disease cannot be an obstacle for those who want to live, you have to have the wisdom to take care of yourself and, with that, you will get new horizons, climbing steps, you slowly learn to control it (I10).

\section{Discussion}

The experience of the illness for people with sickle cell disease is characterized not as a closed process with well-defined sequential phases - they are journeys with different path possibilities involving sequential and/or concurrent events.

From this study, it was observed that in the experience of the illness, people with sickle cell disease define and redefine health care and assess them in their daily lives, often evoking important and essential elements, as their own emotions, and thus building plans and expectations for the future. By doing so, the meaning of care shows close relationship with other elements that are presented in these people's lives.

In that process, through the category "realizing the sickening - the experience of the first moment", these people find out that there is something different, confirming the introduction of changes in behavior, pain, fatigue, malaise, and above all, the impossibility to perform daily tasks ${ }^{(1)}$.

The statements point to allusions to the stereotype of being a strong and productive man. However, these men see themselves as people with a frailty, who lost the power to maintain a strong body as a result of the disease.

Women and men, when faced with a different situation, seek to identify meanings that will allow them to understand what is happening. In the interaction with the body, they perceive the signs of abnormality and suspect that something wrong is happening. This suspicion is part of a constant motion on resolution and decision-making.

What makes them feel sick is the feeling that something is wrong. These experiences with sense are learned and organized into something significant, which makes it possible to relate them to the disease.

After reflecting on the early stages of the illness experience, it is necessary to highlight, in the category "getting to know sickle cell disease better and seeking for care", the world that is around the experience, the context in which the phenomenon materializes. Accordingly, this study confirms data found in other research carried out in Brazil, in which the relationship of these people with the world around them makes all the difference in the way of dealing with the illness and, thus, it can also affect the way these people deal with the context in which they are inserted ${ }^{(8)}$

Due to the experience of physical discomfort, attempts are made to decrease and improve the clinical condition in order to neutralize what they are feeling and continue the path as quickly as possible.

The context of the illness experience is marked by constant struggle to maintain life. Sometimes they find people and environments that serve as support and 
as an incentive element. In other times not so much, considering the stigma, discrimination, and fears that harm the ability of these people to deal with the illness.

All men who have participated in the research have social support from women, whether single or married. Married men enjoy social support from their wives who are responsible for monitoring the adherence to treatment, feeding, and accompany them to medical consultations and during inpatient treatment.

These companions are the first caregivers when pain crises start. In this study we found no man that was independent, that is, that lived alone, and took care of himself without requiring help.

Caring for themselves and the appreciation of the body in the sense of health, as well as the care for others are not issues raised on the socialization of men. It is therefore common for married men to depend on their wives for health care. Thus, marriage works as a protection factor for various illnesses and diseases, which does not happen for women ${ }^{(9)}$.

The approach with health professionals represents an important part of that experience, and specifically with the nursing staff, given the ability to perform care that either meets their needs or not. This approach can also establish new partnerships in the fight against the disease ${ }^{(10)}$.

The interaction established with the health professionals, especially the nursing staff, was identified as constituting a vital element in the definition of care. So, sometimes it is seen that when facing the service in health units these people have a nursing care that has as a characteristic the interaction through caring attitudes, verbal communication, attention and considerate look ${ }^{(10)}$.

It is possible to verify that a separation is made when they talk of nurses and technicians. These nurses are on the front line, so the technician performs technical actions, as prepping the saline solution and applying medication. The nurse examines and the technician communicates the evolution of clinical picture to the nurses, and these people are the ones that are closer.

Intravenous hydration is recommended to be set up as soon as they are admitted to the hospital unit, both for water balance and for the infusion of analgesic medication(11). Venipuncture is a procedure often performed by the nursing staff to people with sickle cell disease.

Usually, these people even get to the health units with signs of dehydration and, consequently, refer to venipuncture as a time of conflict due to the difficulty in puncturing and keeping the and venous access during care ${ }^{(11)}$.
If a communication with these people were established at the moment of performing the techniques, it would be possible to identify issues perceived, based on the meanings attributed to what is occurring. At this point, when seeking for a resolution to the problem presented, there is a need to create the help and trust relationship so that the process becomes the least traumatic as possible. Thus, the interaction with the nursing staff can be subject to stress, when it should be the opposite.

The routine tends to a greater appreciation of physiological aspects at the expense of feelings. The mechanization and speed of tasks in emergency units makes it difficult to realize that these people are more sensitive, requiring much more than technical care, and that fear is very present, as well as other ones(12).

Welcoming is usually a part of the nurse's care, regarded as very good, able to make a difference with a proximity relationship. Knowing how to listen and how to talk are referred to as welcoming actions.

In the context of the chronic disease, the nurse service is also seen in this study as a foundation, providing attention, directions, and guidance through the required confrontations ${ }^{(13)}$.

The importance of the reception performed influences in how they start dealing with the illness and hospitalization experience. Due to the relationship maintained, they feel more confidence in the treatment received, and the nurse care assists in coping with the situation $^{(13)}$.

It is necessary to highlight, from the category "revealing feelings that influence the course of the illness experience", that the person is able to influence the way they consider the illness. With their feelings, beliefs and values they are able to formulate the meaning of the illness and, at the same time, be influenced by it.

A significant problem experienced by people with sickle cell disease is related to the criticism they go through in life because they can feedback the process in a non-satisfactory manner, in spite of the acceptance and understanding of illness ${ }^{(14)}$. So, people around them will be decisive in order to live the illness in a more positive or more negative way.

In this sense, aspects which were also highlighted in this research come into play, as the way they perceive to be seen by other people and the difficulty in dealing with a disease for which there is discrimination(15).

In the perception of the world, discrimination appears as a cross-cutting issue that cuts the experience of these people at various times ${ }^{(14)}$. Thus, 
they find it difficult to deal with a disease that everyone discriminates, that is, they understand that the disease, as well as the color of the skin, leads to discrimination in the social world. In this sense, they state that racial discrimination interferes in social life and in the access to health services, treatment, care and quality of life.

As this chronic condition follows people for life, living with the changes imposed becomes part of everyday life and, based on the life story of each person and the meaning attributed to illness, important decisions are made to provide new meanings to the limitations and the facts ${ }^{(13)}$.

It is noticed that the trajectory of the illness of people with sickle cell disease has its cycle related to the developments of the disease in life, limitations, restrictions and adjustments that are made, as shown in the category "living between limitations and overruns redefining life from care."

The awareness of these limits and the need to face them leads to re-signify the events by setting the facts and establishing an action line compatible with their possibilities at the time in order to achieve the goals and objectives.

In recognizing the circumstances relating to human limitations when dealing with the experience of sickle cell disease, these people appropriate themselves of the resources available to deal with the situation, having clarity on what they may or may not accomplish.

When acknowledging their limits, these people become aware of the difficulties and of the personal and collective effort that they will need to engage in order to solve the problems arising out of the illness ${ }^{(16)}$. It is therefore in this interaction that the possibilities to continue the path and to lead life are rebuilt, constantly having to adapt to new situations and paths.

Due the limitations that occur and that interfere with their daily lives, adjusting to this new reality is a condition for moving on ${ }^{(16)}$. In that process, these people could lose part of their autonomy, especially when the limitation is related to their physical condition.

The need to adapt to the consequences of the chronic illness may involve aspects that are related to the independence that lead to a reorganization of everyday life. The disease is seen as an obstacle that must be overcome. It is necessary to have something to do, run for the goals and live in harmony with the limitations, even because they realize that regardless of the presence of the disease all people have limitations.

Thus, these people are able to redefine its meaning, bring new directions to life and care on the experience of illness. The perception that it is possible to modify the meanings of the events or to face them is a gradual and continuous process of interpretation of events that succeed and result in the search of other relief forms.

Sickle cell disease poses a crisis in people's lives. It's unanimous even to those who experience a less severe illness(16). But these people also mentioned the possibility of overcoming the difficulties, showing that it is possible to redefine the meaning of life, values, care, and relationships.

These people's lives is pervaded by a set of challenges that always requires changes and reassignments. The search for care, in turn, also includes this dynamism. Better knowledge about the disease, the control of crises within the family, and the day to day with the disease leads to the understanding that we need to keep it going despite the disease ${ }^{(12)}$.

In the process of becoming ill, they have the knowledge that health is an evolutionary process and they need to become actors that mobilize actions committed to life, building senses that transcend the aspects of the illness, giving continuity to human experiences, with the limitations but with the capability that they may be updating themselves in every situation which presents itself in the history of each person.

Thus, coexistence requires that efforts be undertaken by subjective plans and goals that interconnect daily into settings and conciliations, between the demands arising from the context of illness, of the course of the disease, the symptoms, the treatment, the care and the answers that sick people give to these problems.

\section{Conclusion}

We consider that the objective of this study was achieved, allowing to expand the understanding of the experience of the illness in people with sickle cell disease, adding knowledge and more elements so that nursing has subsidies for the organization of care in the various levels of health care.

Due to the experience of the illness in people with sickle cell disease in adult life, the importance of nursing care to be properly provided and as sensitive as possible is perceived, because these are people who need tolerance towards their multiple stages of life.

The presence of the nurse in the risk assessment and classification in emergency units would be extremely commendable during the hospitalizations for the evaluation of the evolution of pain and 
nursing consultations in the basic attention service. Unfortunately, however, this is not a reality in Brazil and a lot of these people have never been serviced by nurses in the outpatient level.

It is possible to realize how the nursing was put in the spotlight by being closer to these people and their families, therefore, able to provide humanized service, understanding and supporting them in all their needs during the process of illness.

Taking care of people with sickle cell disease, a genetic chronic disease, is to understand that the coexistence and the relationship of these people with the health services will be permanent and that they will always return to the health services with different demands. Therefore, it is considered that these people need prepared nursing teams, which, in our reality of public health services, many times implies, in the exercise of creativity, overcoming the difficulties imposed by the services.

Nursing care must be implemented in the psychosocial context also, because knowing that these people live between limits and overruns, seeking re-signification of life on the care, nursing has more subsidies to evaluate and enhance the emotional aspects that are present in the experience of living with sickle cell disease.

In this perspective, it is also the responsibility of the nursing team to identify their own design in relation to the people with sickle cell disease, seeking for appropriate, effective and friendly assistance, enabling the minimization of the suffering of all people involved in the care process.

\section{Acknowledgments}

To the people that live with sickle cell disease for taking part in this study.

\section{References}

1. Hirschberg M. [Living with chronic illness: an investigation of its impact on social participation]. Reinnvention: J Undergraduate Res. [Internet]. 2012 [Acesso 12 dez 2013];5(1). Disponível em: http:// www2.warwick.ac.uk/fac/cross_fac/iatl/reinvention/ issues/volume5issue1/hirschberg

2. Gomes LMX, Vieira MM, Reis TC, Barbosa TLA, Caldeira

A. Knowledge of Family health program practitioners in Brazil about sickle cell disease: a descriptive, cross-sectional study. MC Fam Practice 2011;12:89. doi:10.1186/1471-2296-12-89
3. Martins PR, Moraes-Souza $H$, Silveira TB. Morbimortalidade em doença falciforme. Rev Bras Hematol Hemoter. 2010;32(5):378-83.

4. Hunter A, Murphy K, Grealish A, Casey D, Keady J. Navigating the grounded theory terrain. Part 2. Nurse Res. 2011;19(1):6-11.

5. Guion LA, Diehl DC, MacDonald D. Conductingh an in-depth interview. Family Youlth Community Sciences Gainesville: University of Florida; 2011.

6. Dantas CC, Leite JL, Lima SBS, Stipp MAC. Grounded theory - conceptual and operational aspects. Rev. LatinoAm. Enfermagem. 2009;17(4):573-9.

7. Tong A, Sainsbury P, Craig J. Consolidated criteria for reporting qualitative research (COREQ): a 32-item checklist for interviews and focus groups. Int J Qual Health Care 2007;19(6):349-57. doi: http://intqhc. oxfordjournals.org/content/19/6/349.long

8. Pereira SA, Brener S, Cardoso CS, Proietti AB. Sickle Cell Disease: quality of life in patients with hemoglobina SS and SC disorders. Rev Bras Hematol Hemoter. 2013;35(5):325-3.

9. Sánchez-López Mdel P, Cuellar-Flores I, Dresch V. The impact of gender roles on health. Women Health. 2012;52(2):182-96. doi: 10.1080/03630242.2011.652352.

10. Freiermuth CE, Haywood C Jr, Silva S, Cline DM, Kayle M, Sullivan D, et al. Attitudes toward patients with sickle cell disease in a multicenter sample of emergency department providers. Adv Emerg Nurs J. 2014;36(4):335-47. doi: 10.1097/ TME. 0000000000000036 .

11. Porter J, Feinglass J, Artz N, Hafner J, Tanabe P. Sickle cell disease patients' perceptions of emergency department pain management. J Natl Med Assoc. 2012;104(9-10):449-54. English.

12. Adegbola MA, Barnes DM, Opollo JG, Herr K, Gray J, McCarthy AM. Voices of Adults Living with Sickle Cell Disease Pain. J Natl Black Nurses Assoc. 2012;23(2):1623. English.

13. Gallani MC. The nurse in the context of chronic disease. Rev. Latino-Am. Enfermagem. 2015;23(1):1-2. English, Portuguese, Spanish.

14. Haywood C Jr, Lanzkron S, Bediako S, Strouse JJ, Haythornthwaite J, Carroll CP, et al. Perceived discrimination, patient trust, and adherence to medical recommendations among persons with sickle cell disease. J Gen Intern Med. 2014;29(12):1657-62. English.

15. Haywood C Jr, Diener-West M, Strouse J, Carroll CP, Bediako S, Lanzkron $S$, et al. Perceived discrimination 
in health care is associated with a greater burden of pain in sickle cell disease. J Pain Symptom Manage. 2014;48(5):934-43. English.

16. Lekisha YE, Christopher LE. Psychosocial treatments in pain management of sickle cell disease. J Nat Med Assoc. 2010;102(11):1084-94. English. 